\title{
B chromosome in the beetle Coprophanaeus cyanescens (Scarabaeidae): emphasis in the organization of repetitive DNA sequences
}

\author{
Sarah Gomes de Oliveira', Rita Cassia de Moura $^{2}$ and Cesar Martins ${ }^{1 *}$
}

\begin{abstract}
Background: To contribute to the knowledge of coleopteran cytogenetics, especially with respect to the genomic content of B chromosomes, we analyzed the composition and organization of repetitive DNA sequences in the Coprophanaeus cyanescens karyotype. We used conventional staining and the application of fluorescence in situ hybridization (FISH) mapping using as probes Cot-1 DNA fraction, the $18 \mathrm{~S}$ and $5 \mathrm{~S}$ rRNA genes, and the LOA-like non-LTR transposable element (TE).

Results: The conventional analysis detected 3 individuals (among 50 analyzed) carrying one small metacentric and mitotically unstable B chromosome. The FISH analysis revealed a pericentromeric block of Cot-1 DNA in the B chromosome but no $18 \mathrm{~S}$ or $5 \mathrm{~S}$ rDNA clusters in this extra element. Using the LOA-like TE probe, the FISH analysis revealed large pericentromeric blocks in eight autosomal bivalents and in the B chromosome, and a pericentromeric block extending to the short arm in one autosomal pair. No positive hybridization signal was observed for the LOA-like element in the sex chromosomes.

Conclusions: The results indicate that the origin of the B chromosome is associated with the autosomal elements, as demonstrated by the hybridization with $C_{0} t-1$ DNA and the LOA-like TE. The present study is the first report on the cytogenetic mapping of a TE in coleopteran chromosomes. These TEs could have been involved in the origin and evolution of the B chromosome in C. cyanescens.
\end{abstract}

Keywords: Chromosomal rearrangements, Heterochromatin, Multigene families, Supernumerary chromosome, Transposable elements

\section{Background}

Eukaryote genomes are composed of classical genes and genetic elements, including transposable elements (TEs), B chromosomes and several cytoplasmic factors that do not follow Mendelian laws of inheritance [1]. B chromosomes (also called supernumerary or accessory chromosomes) are not essential for the life of a species and are thus considered "dispensable" additional chromosomes. B chromosomes have been observed in approximately $15 \%$ of living species [1-4]. Most B chromosomes are heterochromatic and composed of repetitive DNA sequences, supporting the idea that these chromosomes are non-coding. However, some B chromosomes show the presence of active genes [5-7]. B

\footnotetext{
* Correspondence: cmartins@ibb.unesp.br

'Department of Morphology, Bioscience Institute, UNESP - Sao Paulo State University, Botucatu, SP 18618-970, Brazil

Full list of author information is available at the end of the article
}

chromosomes demonstrate an irregular behavior during mitosis and meiosis that allows them to accumulate in the germ line in a non-Mendelian pattern of inheritance $[3,8]$. Although B chromosomes have been the focus of intensive work in a diversity of eukaryotic species [9-17], several questions concerning their origin, evolutionary mechanism and function remain unanswered.

In Coleoptera, the presence of B chromosomes has been described in approximately 80 species belonging to several families, including Buprestidae [18], Cantharidae [19], Cicindelidae [20] and Scarabaeidae [21,22]. In general, the studies in Coleoptera have concentrated on the presence or absence of B chromosomes in species, with few reports covering their frequency in populations and/or their molecular content [18,21-23]. There are a few reports on the presence of B chromosomes in the Scarabaeidae family, including species of the Scarabaeinae and Cetoniinae 
subfamilies [21,22]. Among scarabaeines, the Coprophanaeus species (Phanaeine) showed similar karyotypes consisting of $2 n=20$ and meta-submetacentric chromosomes with a gradual reduction in size, three types of sex chromosomes mechanisms ( $\mathrm{XY}, \mathrm{Xy}, \mathrm{XY}_{\mathrm{p}}$ ), a high amount of constitutive heterochromatin, and there is no description of B chromosomes for this group until now [24-26]. Besides their karyotype characteristics, the phaneines are restricted to the Neotropical region and play an important role in the ecosystems including nutrient recycling [27-29].

Although the cytogenetic mapping of repetitive DNA sequences has been performed for several species of coleopterans, the data are limited to the analysis of satellite DNA, rRNA and H3 histone genes e.g. [22,2426,30-34]. Based in the heterochromatic nature of the $B$ chromosomes and that several families of TEs are particularly enriched in heterochromatin, it is particularly interesting the analysis of $\mathrm{TE}$ sequences in relation to their organization in B chromosomes. Considering the gap of knowledge on the genomic content of Coleoptera B chromosomes, the present work performed molecular cytogenetic mapping of repetitive DNAs in the beetle Coprophanaeus cyanescens, with emphasis in the investigation of the B chromosome.

\section{Results}

The standard karyotype observed in C. cyanescens was $2 \mathrm{n}=$ 20, $\mathrm{XY}_{\mathrm{p}}$ ("p" refers to a "parachute" meiotic conformation between the $\mathrm{X}$ and $\mathrm{Y}$ ), with meta-submetacentric chromosomes that showed a gradual reduction in size (Figure 1a). In addition, three individuals among the 50 analyzed (6\%) carried 1 small-sized B meta-submetacentric chromosome. For each individual carrying the B chromosome, at least 30 metaphase I stages were analyzed, and $13.8 \%$ of the cells did not present the extra chromosome, indicating mitotic instability. The B chromosome had a condensation pattern similar to that of the autosomal chromosomes and was easily recognized as a small univalent structure in metaphase I (Figure 1).

The FISH analysis using the $C_{0} t-1$ DNA probe revealed positive hybridization in the long arms of all the autosomal chromosomes and the $\mathrm{X}$ and $\mathrm{Y}$ chromosome and in a pericentromeric block in the B chromosome (Figure $1 \mathrm{~b}$ ). The chromosomal mapping using the $18 \mathrm{~S}$ and $5 \mathrm{~S}$ rDNA probes showed clusters on distinct chromosomes (Figure 1c). The $18 \mathrm{~S}$ rDNA clusters were observed at nine sites (four autosomal pairs plus one single chromosome), and the 5S rDNA clusters were observed at two sites (one autosomal pair) (Figure 1c).
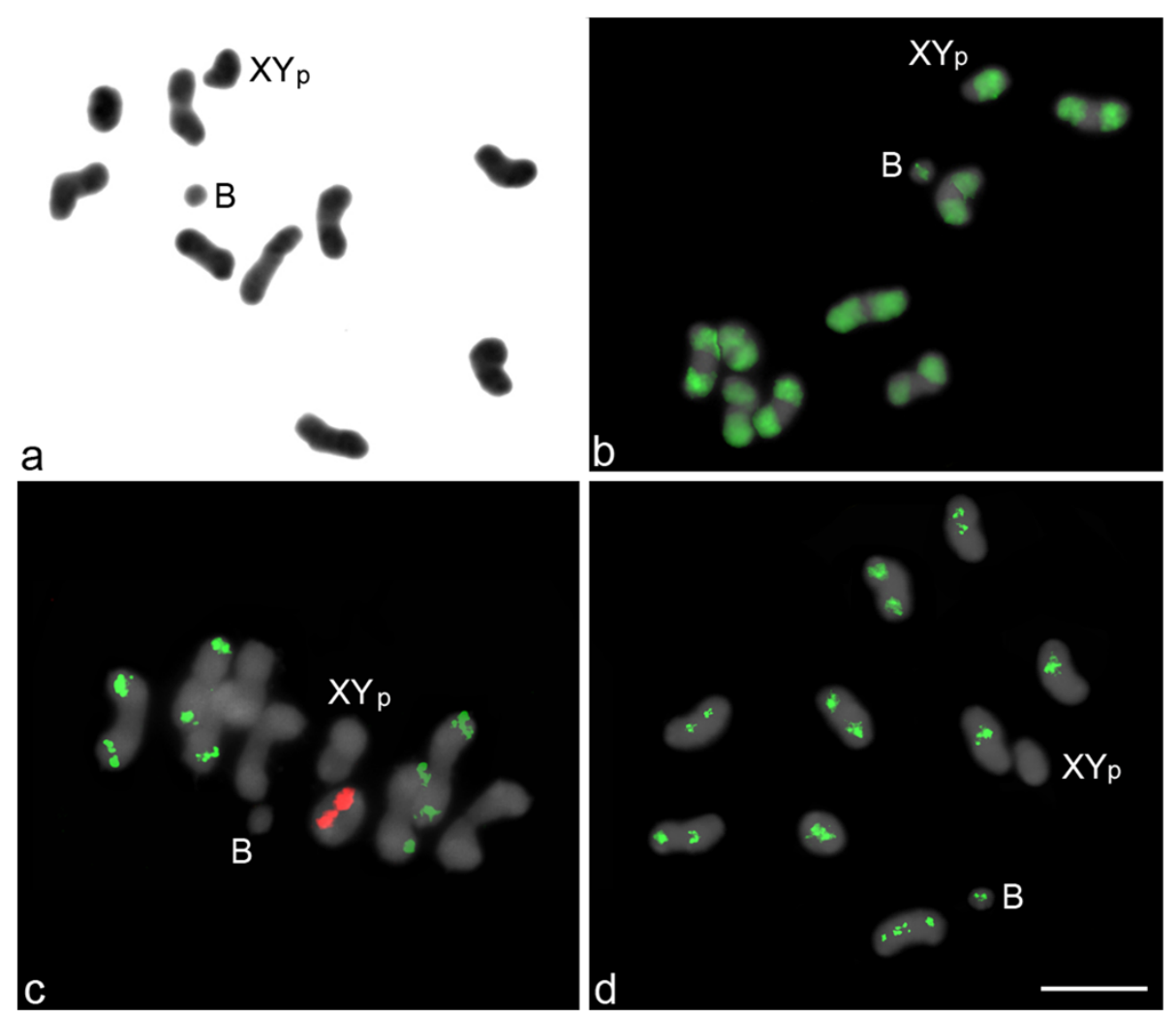

Figure 1 Metaphase I stages of Coprophanaeus cyanescens carrying 1 B chromosome. Conventional staining (a), FISH mapping of $C_{0} t-1$ DNA (b), $18 \mathrm{~S}$ (green) and $5 \mathrm{~S}$ (red) rRNA genes (c) and LOA-like non-LTR retrotransposon (d). The B chromosome and the XYp sex chromosomes are indicated. Bar $=5 \mu \mathrm{m}$. 
None of the rDNA probes hybridized with the B chromosome (Figure 1c).

Analysis of the non-LTR retrotransposon sequence (hereafter named the LOA-like non-LTR retrotransposon), which was isolated by polymerase chain reaction (PCR) and subsequently cloned, revealed a segment of $223 \mathrm{bp}$ that shared $\sim 65 \%$ similarity to the Baggins-1_Nvi family previously identified in Nasonia vitripennis [35]. The alignment of these sequences is shown in Additional file 1. FISH analysis using probes for the LOA-like element revealed large pericentromeric blocks in eight autosomal bivalents and the B chromosome and a pericentromeric block extending to the short arm in one autosomal pair; a positive hybridization signal was not observed in the sex chromosomes (Figure 1d).

\section{Discussion}

Basic characteristics of the $C$. cyanescens karyotype

The basic karyotype structure for C. cyanescens (composed of $2 \mathrm{n}=20, \mathrm{XY}_{\mathrm{p}}$, with meta-submetacentric chromosomes) is in concordance with previous karyotype data reported for Coprophanaeus species [26,31,32]. However, this is the first study to identify a B chromosome in this species as well as in the Phanaeini tribe. In contrast to the small size of the B chromosome observed in C. cyanescens, the B chromosomes were medium- or large-sized in the other Scarabaeidae species [21,22,36]. In Onthophagus vacca, the presence of one mediumsized B chromosome was observed with the presence of heterochromatin in its centromeric region, whereas Onthophagus similis and O. gazella showed respectively medium- and small-sized B chromosomes; however, there was no information about the heterochromatic pattern. Large heterochromatic B chromosomes, ranging in number from three to nine, were detected in all the specimens studied for Bubas bubalus [21]. Individuals carrying one heterochromatic B chromosome in two populations of Dichotomius geminatus, corresponding to an average prevalence rate of $20.93 \%$ and $25.00 \%$ in each of the populations, were observed [22].

The frequency with which $\mathrm{B}$ chromosomes are detected in natural populations varies widely between populations. B chromosomes can be present in high frequencies based on the degree to which a species can tolerate the extra chromosome and their power of accumulation [23]. It is difficult to determine the factors that are involved in the low frequency of B chromosomes in the population studied, and several mechanisms may be involved, including selection, random transmission, and historical factors.

Among Coleoptera species, the studies reporting the presence of $\mathrm{B}$ chromosomes have generally focused on the presence or absence of this element and have not considered their frequency in the population or their molecular content $[18,21,23,36]$. The presence of B chromosomes was reported in representatives of the Cetoniinae and Scarabaeinae, subfamilies of Scarabaeidae [21,22]. The evolution of the Scarabaeinae karyotype appears to have occurred under diverse mechanisms of chromosomal rearrangements [37], which could have contributed to the origin of the $\mathrm{B}$ chromosome in this group.

\section{Molecular cytogenetic mapping of $C$. cyanescens}

The hybridization of the $C_{0} t-1$ DNA to the pericentromeric regions extending up to the long arms of $C$. cyanescens chromosomes is in agreement with the heterochromatin distribution pattern observed in this species [26]. Although heterochomatin analyses were not conducted in the present work, the accumulation of repeated DNAs in the pericentromeric region of the B suggests also the compartimentalization of heterochromatin in the same region. The formation of the heterochromatic chromocenters in the Phanaeini species $[38,39]$ indicates that this mechanism of heterochromatin amplification may be involved in the formation of diphasic chromosomes, including the large pericentromeric block of the $\mathrm{B}$ chromosome.

The distribution of $C_{0} t-1$ DNA in the A complement and the $\mathrm{B}$ chromosome suggests an intraspecific origin of the extra element and the occurrence of homogenization mechanisms in the heterochromatic regions between the $\mathrm{B}$ and A elements. Generally, B chromosomes of more recent origin are enriched in repetitive DNA sequences when compared with the genome from which they originated $[1,23]$. This enrichment is indicative of a massive amplification of repetitive sequences over a relatively short time-scale; and, it has also been suggested that repetitive sequences amplification may be a mechanism through which a chromosome fragment (as a neo-B chromosome) may become stabilized and selected $[1,23]$. This does not appear to be the case for $C$. cyanescens, indicating that the $\mathrm{B}$ chromosome may not have been recently established in this species. Although the data obtained indicates an intraspecific origin of the $\mathrm{B}$ chromosome, it was not possible to identify which chromosomal A element was involved in the process. However, the chromosomes carrying the $5 \mathrm{~S}$ and $18 \mathrm{~S}$ RNA genes are probably not involved in this process, as the B element does not contain rRNA gene sequences.

The cytogenetic mapping of the LOA-like non-LTR retrotransposon mostly to the pericentromeric regions, including those of the $\mathrm{B}$ chromosome, indicates the exchange of genetic material between the $\mathrm{A}$ and $\mathrm{B}$ chromosomes, implying that the $\mathrm{B}$ chromosome has coexisted with the A chromosomes during the period of transposition. However, it is not possible to reject the hypothesis that the $\mathrm{B}$ chromosome originated from a segment without LOA-like that was received later, by transposition. According to a previous report [40], B 
chromosomes can accumulate DNA from various sources, including transposable elements, and may affect the structure of the genome by ectopic recombination. A study in Drosophila melanogaster identified 25 transposonmediated rearrangements by ectopic recombination in the region flanking the white locus [41]. The B chromosomes could act as a refuge for TEs, which in turn would generate structural variability in the whole genome. The hybridization that occurred in homologous regions, such as the pericentromeric regions, is another indication of recombination between the A complement and the B chromosome, and this recombination event could be explained by the chromocenter formation during the beginning of meiosis [37].

The present study is the first report on the cytogenetic mapping of a transposable element in coleopteran chromosomes. The LOA non-LTR retrotransposon was first isolated from the genome of Drosophila silvestris, a species that is endemic to the Hawaiian Islands [42]. These elements belong to evolutionarily younger clades of nonLTR retrotransposons [43], contain very few known elements, and have mostly been identified in Drosophila, Aedes and Ciona genomes [44].

The distribution of LOA-like elements in the chromosomes reinforces an evolutionary relationship between the A complement and the B chromosome at least in the pericentromeric area. Recent work involving the centromere-enriched retrotransposons indicates that these elements preferentially insert into the centromeric regions [45]. The LOA-like elements may have been maintained in the genome of $C$. cyanescens due to a possible functional role they play in the maintenance of the pericentromeric regions. The absence of LOA-like elements in the sex chromosomes suggests that sex differentiation occurs before the distribution of this transposable element into the genome. Subsequently, the suppression of recombination could have produced the differences observed in the distribution of TEs between the A complement and the sex chromosomes. These results suggest that $L O A$-like element could have been involved in the maintenance of the pericentromeric regions and might contribute to the origin of the $B$ chromosome.

\section{Conclusions}

The results obtained by the hybridization of $C_{0} t-1$ DNA and the LOA-like non-LTR retrotransposon indicate that the origin of the B chromosome is associated with autosomal elements. The present study is the first report on the cytogenetic mapping of a transposable element in coleopteran chromosomes. Our work further suggests that TEs could also have been involved in the origin and evolution of the B chromosome in C. cyanescens.

\section{Methods}

\section{Animal sampling and cytogenetic analysis}

Fifty adult specimens of Coprophanaeus cyanescens (Olivier, 1789) (Coleoptera: Scarabaeidae: Scarabaeinae: Phanaeini) were obtained from Parque João Vasconcelos Sobrinho, Caruaru, Pernambuco State, Brazil. The specimens were collected in the wild according to Brazilian laws for environmental protection (wild collection permit, MMA/IBAMA/SISBIO $n^{\circ}$. 2376-1). The experimental research on animals was conducted according to the international guidelines followed by São Paulo State University (Protocol no. 35/08 - CEEA/IBB/UNESP).

The testes were fixed in Carnoy solution (3:1 ethanol: acetic acid) and later stored at $-20^{\circ} \mathrm{C}$. The chromosome preparations were obtained by using the classical testicular follicle squashing technique. Conventional chromosome analysis was performed after staining the slides with $5 \%$ Giemsa.

\section{Chromosomal probe isolation}

The DNA samples were obtained from frozen tissues collected from specimens. The procedure for extraction of genomic DNA followed the protocol previously described [46] with minor modifications. The quality and quantity of purified DNA was evaluated in $0.8 \%$ agarose gel and spectrophotometry.

Three sets of DNA sequences were used as probes for fluorescence in situ hybridization (FISH) as follow: (i) sequences for the $18 \mathrm{~S}$ and $5 \mathrm{~S}$ rRNA genes were obtained from cloned sequences of the dung beetle, Dichotomius semisquamosus [22]; (ii) sequences of the LOA-like nonLTR retrotransposon were obtained from $C$. cyanescens by PCR with the RF-Co (5' CGC CTA CTT CAG GAC CAG AG 3') and RR-Co (5' AGA CTG CAG GCC GTA GAA AA 3') primers [47]; (iii) $C_{0} t-1$ DNA sequences were isolated from $C$. cyanescens based on the DNA reassociation kinetics [48] with modifications [49].

PCR products from the non-LTR retrotransposons were inserted into the pGEM-T plasmid (Promega) according to the manufacturer's recommendations, and the recombinant plasmids were used to transform competent Escherichia coli cells (Invitrogen, San Diego, CA, USA). The presence of the inserts in the recombinant plasmids was analyzed by PCR, and the recombinant clones were stored at $-80^{\circ} \mathrm{C}$. The recombinant plasmids were subjected to nucleotide sequencing using an Applied Biosystems sequencer (3500 Genetic Analyzer).

\section{Analysis of transposable elements}

The LOA-like non-LTR retrotransposon sequences isolated by PCR from C. cyanescens were used as queries to detect related TEs in other genomes available from the Repbase (http://www.girinst.org/repbase/) and NCBI (National Center for Biotechnology Information - http:// 
www.ncbi.nlm.nih.gov/) databases. The search included whole genome shotgun contigs, nucleotide collections, and high throughput genomic sequences. Analysis of the recovered DNA sequences were performed with the LIRMM software (Laboratoire Le d'Informatique, Robotique et de Microélectronique of Montpellier) available online (http://www.phylogeny.fr/) [50-52].

\section{Fluorescence in situ hybridization}

The DNA probes were labeled by nick translation with biotin-11-dATP (Invitrogen) or digoxigenin-11-dUTP (Roche, Mannheim, Germany) by PCR. The FISH technique was performed according to a protocol adapted for Coleoptera [22]. The chromosome spreads were counterstained with DAPI (4', 6-diamidino-2-phenylindole), and the slides were mounted in Vectashield mounting medium (Vector, Burlingame, CA, USA). The images were captured using an Olympus DP71 digital camera coupled to a BX61 Olympus microscope and were optimized for brightness and contrast using Adobe Photoshop CS2 and Corel Photo-Paint 13.

\section{Additional file}

Additional file 1: Alignment of the LOA non-LTR retrotransposon nucleotide sequences from Nasonia vitripennis (Baggins-1_NVi) and Coprophanaeus cyanescens (Cc-1 to Cc-3). The asterisks $\left(^{*}\right)$ indicate similarity in sequence, and the dashes (-) indicate indels.

\section{Abbreviations}

CEEA: Comissão de Ética em Experimentação Animal; DAPI: 4' 6-Diamidino-2Phenylindole; FISH: Fluorescence In Situ Hybridization; IBAMA: Instituto Brasileiro do Meio Ambiente e dos Recursos Naturais Renováveis; IBB: Instituto de Biociências de Botucatu; LIRMM: Laboratoire Le d'Informatique, Robotiqueet de Microélectronique of Montpellier; LTR: Long Terminal Repeat; MMA: Ministério do Meio Ambiente; NCBI: National Center for Biotechnology Information; PCR: Polymerase Chain Reaction; rDNA: ribosomal DNA; rRNA: ribosomal RNA; SISBIO: Sistema de Autorização e Informação em Biodiversidade; UNESP: Universidade Estadual Paulista; TE(s): Transposable Element(s).

\section{Competing interests}

The authors declare that they have no competing interests.

\section{Authors' contributions}

SGO, RCM and CM contributed to the development of the hypothesis, specimen collection and preparation, and analysis and interpretation of data. SGO and CM drafted the first version of the manuscript. RCM revised the manuscript. All authors read and approved the final manuscript.

\section{Acknowledgements}

The authors are grateful to CMQ Costa and FAB Silva for the taxonomic identification of the studied species. The study was supported by the Fundação de Amparo à Pesquisa do Estado de São Paulo (FAPESP), the Fundação de Amparo à Ciência e Tecnologia do Estado de Pernambuco (FACEPE), the Conselho Nacional de Desenvolvimento Científico e Tecnológico (CNPq) and the Coordenadoria de Aperfeiçoamento de Pessoal de Nível Superior (CAPES) of Brazil.

\section{Author details}

'Department of Morphology, Bioscience Institute, UNESP - Sao Paulo State University, Botucatu, SP 18618-970, Brazil. ²Department of Biology, Biological Sciences Institute, UPE - Pernambuco State University, Recife, PE 50100-130, Brazil.
Received: 20 August 2012 Accepted: 4 November 2012

Published: 6 November 2012

\section{References}

1. Camacho JP, Sharbel TF, Beukeboom LW: B-chromosome evolution. Phil Trans R Soc Lond B 2000, 355:163-178.

2. White MJD: Animal Cytology and Evolution. 3rd edition. London: Cambridge University; 1973

3. Jones RN: B-chromosome drive. Am Nat 1991, 137:430-442.

4. Palestis BG, Trivers R, Burt A, Jones RN: The distribution of $B$ chromosomes across species. Cytogenet Genome Res 2004, 106:151-158.

5. Green DM: Structure and evolution of B chromosomes in amphibians. Cytogenet Genome Res 2004, 106:235-242.

6. Marschner S, Meister A, Blattner FR, Houben A: Evolution and function of B chromosome $45 \mathrm{~S}$ rDNA sequences in Brachycome dichromosomatica. Genome 2007, 50:638-644.

7. Houben A, Nasuda S, Endo TR: Plant B chromosome. Methods Mol Biol 2011, 701:97-111.

8. Kean VM, Fox DP, Faulkner R: The accumulation mechanism of the supernumerary (B-) chromosome in Picea sitchensis (Bong.) Carr. and the effect of this chromosome on male and female flowering. Silvae Genet 1982, 31:126-131.

9. Houben A, Kynast RG, Heim U, Hermann H, Jones RN, Forster JW: Molecular cytogenetic characterization of the terminal heterochromatic segment of the B chromosome of rye (Secale cereale). Chromosoma 1996, 105:97-103.

10. Houben $A$, Leach $C R$, Verlin D, Rofe R, Timmis JN: A repetitive DNA sequence common to the different $B$ chromosomes of the genus Brachycome. Chromosoma 1997, 106:513-519.

11. McAllister BF, Werren JH: Hybrid origin of a B chromosome (PSR) in the parasitic wasp Nasonia vitripennis. Chromosoma 1997, 106:243-253.

12. Sharbel TF, Green DM, Houben A: B chromosome origin in the endemic New Zealand frog Leiopelma hochstetteri through sex chromosome evolution. Genome 1998, 41:14-22.

13. Goodwin SB, M'Barek SB, Dhillon B, Wittenberg AHJ, Crane CF: Finished genome of the fungal wheat pathogen Mycosphaerella graminicola reveals dispensome structure, chromosome plasticity, and stealth pathogenesis. PLoS Genetics 2001, 7:e1002070

14. Perfectti $F$, Werren $\mathrm{JH}$ : The interspecific origin of $B$ chromosomes: experimental evidence. Evolution 2001, 55:1069-1073.

15. Bertolotto CEV, Pellegrino KCM, Yonenaga-Yassuda Y: Occurrence of B chromosomes in lizards: a review. Cytogenet Genome Res 2004, 106:243-246.

16. Coluccia E, Cannas R, Cau A, Deiana AM, Salvadori S: B chromosomes in Crustacea Decapoda. Cytogenet Genome Res 2004, 106:215-221.

17. Borisov $Y M$ : The polymorphism and distribution of $B$ chromosomes in germline and somatic cells of Tscherskia triton de Winton (Rodentia, Cricetinae). Russ J Genet 2012, 48:538-542

18. Moura RC, Melo NF, Souza MJ: High levels of chromosomal differentiation in Euchroma gigantean L 1735 (Coleoptera, Buprestidae). Gen Mol Biol 2008, 31:431-437.

19. James LV, Angus RB: A chromosomal investigation of some British Cantharidae (Coleoptera). Genetica 2007, 130:293-300.

20. Proença SJR, Serrano ARM, Collares-Pereira MJ: Cytogenetic variability in genus Odontocheila (Coleoptera, Cicindelidae): karyotypes, C-banding, NORs and localization of ribosomal genes of $O$. confusa and $O$. nodicornis. Genetica 2002, 114:237-245.

21. Angus RB, Wilson CJ, Mann DJ: A chromosomal analysis of 15 species of Gymnopleurini and Coprini (Coleoptera: Scarabaeidae). Tijdsch Voor Entomol 2007, 150:201-211.

22. Cabral-de-Mello DC, Moura RC, Martins C: Chromosomal mapping of repetitive DNAs in the beetle Dichotomius geminatus provides the first evidence for an association of $5 \mathrm{~S}$ rRNA and histone $\mathrm{H} 3$ genes in insects, and repetitive DNA similarity between the $B$ chromosome and $A$ complement. Heredity 2010, 104:393-400.

23. Camacho JPM: B Chromosomes. In The Evolution of the Genome. Edited by Gregory TR. San Diego: Elsevier; 2005:223-286.

24. Palomeque T, Muñoz-López M, Carrillo JA, Lorite P: Characterization and evolutionary dynamics of a complex family of satellite DNA in the leaf beetle Chrysolina carnifex (Coleoptera, Chrysomelidae). Chrom Res 2005, 13:795-807.

25. Cabral-de-Mello DC, Moura RC, Carvalho R, Souza MJ: Cytogenetic analysis of two related Deltochilum (Coleoptera, Scarabaeidae) species: diploid 
number reduction, extensive heterochromatin addition and differentiation. Micron 2010, 41:112-117.

26. Oliveira SG, Moura RC, Silva AEB, Souza MJ: Cytogenetic analysis of two Coprophanaeus species (Scarabaeidae) revealing wide constitutive heterochromatin variability and the largest number of $45 \mathrm{~S}$ rDNA sites among Coleoptera. Micron 2010, 41:960-965.

27. Edmonds WD: Comparative skeletal morphology, systematics and evolution of the Phanaeine dung beetles (Coleoptera: Scarabaeidae). Kans Univ Sci Bull 1972, 49:731-874.

28. Philips TK, Edmonds WD, Scholtz CH: A phylogenetic analysis of the New World tribe Phanaeini (Coleoptera: Scarabaeidae: Scarabaeinae): Hypotheses on relationships and origins. Insect Syst Evol 2004, 35:43-63.

29. Edmonds WD, Zidek JA: Taxonomic review of the neotropical genus Coprophanaeus Olsoufieff, 1924 (Coleoptera: Scarabaeidae, Scarabaeinae). Insecta Mundi 2010, 129:1-111.

30. Bione EG, Moura RC, Carvalho R, Souza MJ: Karyotype, C-banding pattern NOR location and FISH study of five Scarabaeidae (Coleoptera) species. Gen Mol Biol 2005, 28:376-381.

31. Oliveira SG, Cabral-de-Mello DC, Arcanjo AP, Xavier C, Souza MJ, Martins C, Moura RC: Heterochromatin, sex chromosomes and rRNA gene clusters in Coprophanaeus beetles (Coleoptera, Scarabaeidae). Cytogenet Genome Res 2012, 138:46-55.

32. Cabral-de-Mello DC, Oliveira SG, Moura RC, Martins C: Chromosomal organization of the $18 \mathrm{~S}$ and $5 \mathrm{~S}$ rRNAs and histone $\mathrm{H} 3$ genes in Scarabaeinae coleopterans: insights into the evolutionary dynamics of multigene families and heterochromatin. BMC Genet 2011, 12:88.

33. Pons J, Bruvo B, Juan C, Petitpierre E, Plohl M, Ugarkovic D: Conservation of satellite DNA in species of the genus Pimelia (Tenebrionidae, Coleoptera). Gene 1997, 255:183-190.

34. Gálian J, Vogler AP: Evolutionary dynamics of a satellite DNA in the tiger beetle species pair Cicindela campestris and C. maroccana. Genome 2003, 46:213-223.

35. Jurka J: LINE retrotransposons from the parasitic wasp Nasonia vitripennis. Repbase Reports 2009, 9:483-483.

36. Wilson CJ, Angus RB: A chromosomal analysis of 21 species of Oniticellini and Onthophagini (Coleoptera: Scarabaeidae). Tijdschr Entomol 2005, 148:63-76.

37. Cabral-de-Mello DC, Oliveira SG, Ramos IC, Moura RC: Karyotype differentiation patterns in species of the subfamily Scarabaeinae (Scarabaeidae, Coleoptera). Micron 2008, 39:1243-1250.

38. Bione EG, Camparoto ML, Simões ZL: A study of the constitutive heterochromatin and nucleolus organizer regions of Isocopris inhiata and Diabroctis mimas (Coleoptera: Scarabaeidae, Scarabaeinae) using C-banding, AgNO3 staining and FISH techniques. Gen Mol Biol 2005, 28:111-116.

39. Colomba M, Vitturi R, Libertini A, Gregorini A, Zunino M: Heterochromatin of the scarab beetle, Bubas bison (Coleoptera: Scarabaeidae) II. Evidence for AT-rich compartmentalization and a high amount of rDNA copies. Micron 2006, 37:47-51

40. Beukeboom LW: Bewildering Bs: an impression of the 1st B-chromosome conference. Heredity 1994, 73:328-336.

41. Montgomery E-A, Huang S-M, Langley CH, Judd BH: Chromosome rearrangement by ectopic recombination in Drosophila melanogaster: genome structure and evolution. Genetics 1991, 129:1085-1098.

42. Felger I, Hunt JA: A non-LTR retrotransposon from the Hawaiian Drosophila: the LOA element. Genetica 1992, 85:119-130.

43. Volff J-N, Lehrach H, Reinhardt R, Chourroutà D: Retroelement dynamics and a novel type of chordate retrovirus-like element in the miniature genome of the tunicate Oikopleura dioica. Mol Biol Evol 2004, 21:2022-2033.

44. Rho M, Tang H: MGEScan-non-LTR: computational identification and classification of autonomous non-LTR retrotransposons in eukaryotic genomes. Nuc Acids Res 2009, 37:e143.

45. Birchler JA, Presting GG: Retrotransposon insertion targeting: a mechanism for homogenization of centromere sequences on nonhomologous chromosomes. Genes Dev 2012, 26:638-640.

46. Sambrook J, Russel DW: Molecular Cloning. A Laboratory Manual. Third Editionth edition. Cold Spring Harbor: Cold Spring Harbor Laboratory Press; 2001.

47. Burke WD, Eickbush DG, Xiong Y, Jakubczak J, Eickbush TH: Sequence relationship of retrotransposable elements $\mathrm{RI}$ and $\mathrm{R} 2$ within and between divergent insect species. Mol Biol Evol 1993, 10:163-185.
48. Zwick MS, Hanson RE, McKnight TD, Nurul-Islam-Faridi M, Stelly DM: A rapid procedure for the isolation of $C_{0} t-1$ DNA from plants. Genome 1997, 1997(40):138-142.

49. Ferreira IA, Martins C: Physical chromosome mapping of repetitive DNA sequences in Nile tilapia Oreochromis niloticus: evidences for a differential distribution of repetitive elements in the sex chromosomes. Micron 2008, 39:411-418.

50. Guindon S, Gascuel O: A simple, fast, and accurate algorithm to estimate large phylogenies by maximum likelihood. Syst Biol 2003, 52:696-704.

51. Chevenet F, Brun C, Banuls AL, Jacq B, Christen R: TreeDyn: towards dynamic graphics and annotations for analyses of trees. $B M C$ Bioinformatics 2006, 7:439.

52. Dereeper A, Guignon V, Blanc G, Audic S, Buffet S, Chevenet F, Dufayard J-F, Guindon S, Lefort V, Lescot M, Claverie J-M, Gascuel O: Phylogeny.fr: robust phylogenetic analysis for the non-specialist. Nucleic Acids Res 2008, 36:465-469.

doi:10.1186/1471-2156-13-96

Cite this article as: Gomes de Oliveira et al: B chromosome in the beetle Coprophanaeus cyanescens (Scarabaeidae): emphasis in the organization of repetitive DNA sequences. BMC Genetics 2012 13:96.

\section{Submit your next manuscript to BioMed Central and take full advantage of:}

- Convenient online submission

- Thorough peer review

- No space constraints or color figure charges

- Immediate publication on acceptance

- Inclusion in PubMed, CAS, Scopus and Google Scholar

- Research which is freely available for redistribution 